\title{
LXXIII. The production and origin of radium
}

\section{E. Rutherford F.R.S.}

To cite this article: E. Rutherford F.R.S. (1907) LXXIII. The production and origin of radium , Philosophical Magazine Series 6, 14:84, 733-749, DOI: 10.1080/14786440709463736

To link to this article: http://dx.doi.org/10.1080/14786440709463736

册 Published online: 16 Apr 2009.

Submit your article to this journal 준

Џ Article views: 9

Q View related articles $₫$ 
surface; the amount of emanation in the atmosphere; the resulting active deposit; the penetrating radiation due to all these; the ionization in the atmosphere: all are of the correct order of magnitude, so that they may be correlated.

Result.-The emanation in the atmosphere is absorbed by coconut-charcoal: its presence can be proved and its magnitude determined.

Four measurements have been made at Montreal, and the results are given in terms of the amount of radium required to maintain the supply per cubic metre constant. The smallest value obtained was $24 \times 10^{-12}$, the largest $127 \times 10^{-12}$. The probable average value is $80 \times 10^{-12}$. The amount of emanation is of the correct order to account for the active deposits of radium $\mathrm{C}$, which may be collected on negativelycharged wires from the atmosphere.

Now that Professor Rutherford has left McGill University, I wish to state my indebtedness to him. If my papers have had any merit, it may be attributed, without exaggeration, to his influence or inspiration, and for these I am grateful.

McGill University, Montreal, Angust 1907 .

LXXIIT. The Production and Origin of Radium. By E. Rutherford, F.R.S., Professor of Physics, University of Manchester*

$\S 1$. TWHE present point of view of regarding radium as a substance which is undergoing slow transformation was first put forward definitely by Rutherford and Soddy in the paper entitled "Radioactive Change" (Phil. Mag. May 1903, p. 590) in the following terms:- "In the case of radium, however, the same amount (viz. about 1 milligram) must be changing per gram per year. The 'life' of the radium cannot in consequence be more than a few thousand years on this minimum estimate, based on the assumption that each particle produces one ray at each change.... So that it appears certain that the radium present in a mineral has not been in existence as long as the mineral itself, but is being continuously produced by radioactive change."

On this theory, the parent substance which produces radium must always be present in minerals containing radium. Uranium from the first appeared to be the most probable

* Communicated by the Author, having been read before the British Association, Leicester, August $190 \%$. Previous accounts of the results were given in letters to 'Nature,' Jan. 17 and June 6, 1907. 
parent, since it possessed a life long compared with radium and was always found associated with it. There were two obvious methods of attack to throw light upon this question, one direct and the other indirect. The first consisted in an examination to see whether in course of time radium appeared in a solution of uranium initially freed from radium. The second depended upon an examination of the relative amount of radium and uranium in radioactive minerals. According to theory, if uranium is the parent of radium, the ratio of the amount of radium in any mineral to that of uranium should be constant. The constancy of this ratio has been completely substantiated by the independent work of Boltwood*, Strutt $\uparrow$, and McCoy $\$$; and there can be no doubt that uranium and radium are genetically connected. Rutherford and Boltwood $\S$ have found that for every gram of uranium in a mineral, there is present $3.8 \times 10^{-7} \mathrm{gram}$ of radium.

The question of the growth of radium in a uranium solution was first attacked by Soddy $\|$, and later by Boltwood $T$. Without entering into the details of these important investigations, it suffices to say that, in carefully purified uranium solutions, no growth of radium bas been observed, over the space of the few years that observations have been in progress. If radium is produced at all, it is certainly produced at less than $1 / 1000$ of the rate to be expected theoretically. This result is not necessarily inconsistent with the view that radium is a transformation product of uranium, for the absence of observable growth of radium in a limited time is to be expected, if one or more products of slow transformation exist between uranium and radium.

In the meantime, Boltwood ** had approached the problem from a different direction. By a special method, the actinium was separated from a kilogram of carnotite. A solution of this actinium, initially containing very little radium, was placed aside and examined 120 days afterwards. A notable increase in the amount of radium was observed. In addition, the rate of growth in this interval was about that to be expected if radium were half transformed in about 2000 years -a result in conformity with calculations of the probable life of radium. The work of Boltwood marks a definite and

* Boltwood, Phil. Mag. April 1905.

+ Strutt, Proc. Roy. Soc. March 2, 1905.

McCoy, Ber. d. D. Chem. Ges. No. 11, p. 2641, 1905.

Rutherford and Boltwood, Amer. Journ. Sci. July 1906.

Soddy, Phil. Mag. June 1905, Aug. 1907.

II Boltwood, Amer. Journ. Sci. Sept. 1905.

** Boltwood, 'Nature,' Nov. 15, 1906. 
important stage in the attack on this problem, for it clearly shows that radium, as theory predicted, is produced from another substance and that this parent substance is normally present with actinium.

Boltwood concluded that actinium was the direct parent of radium and was itseif an intermediate product between uranium and radium. This conclusion was strongly supported by his observation that the amount of actinium in minerals, like the amount of radium, was proportional to the amount of uranium. Since actinium has probably a life comparable with that of radium, such a conclusion is consistent with the observed absence of growth of radium in uranium solutions, for the uranium must first form a considerable quantity of actinium before the transformation product of the latter, viz. radium, could be detected in the solution. This question will be discussed later in the paper after the consideration of further experimental results. It will be seen that the problem is more complicated than at first appeared.

\section{§2. Old Eaperiments.}

It may be of interest to give a brief account of some experiments commenced by myself in 1904 to determine whether radium was continuously produced from actinium. A pre liminary account of this work was given in the Bakerian Lecture (Phil. Trans. A, p. 218, 1904). Two grams of an active preparation, of activity about 250 times that of uranium, obtained from Giesel, were taken and dissolved in acid. The initial content of radium was determined by the emanation method, and the greater part of it then removed by successive precipitations in the solution of small quantities of barium as sulphate. Measurements were then made of the amount of radium in this solution at intervals over a space of three months, but with no certain evidence of the growth of radium. The amount of radium was estimated by the emanation method. The radium emanation, which was allowed to collect in the solution for a known interval, was removed into a large electroscope by aspirating a considerable amount of air through the solntion. Later work of Boltwood has shown that this aspiration method is unreliable for an accurate determination of the amount of radium present, but it no doubt serves for comparative measurements under identical conditions.

In the light of later knowledge, the method employed for the separation of the radium present initially in the solution 
was very unsuitable for several reasons. A trace of sulphuric acid remaining in the solution after the removal of the barium might possibly precipitate the radium as sulphate -a form in which it would be very unlikely to release all its emanation by aspiration of the solution.

After three months' observations, this solution was put aside with the intention of testing its radium content at intervals; but the pressure of other work and the recognition of the danger of contaminating the solution in a laburatory in which a large quantity of radium was in use, led to a postponement of further tests for a period of over two and a half years. On the appearance of Boltwood's paper I immediately examined this solution to see whether there had been a growth of radium in this long interval. A preliminary test showed that there had been a considerable increase in the content of radium, but in making a more accurate determination, the solution was unfortunately contaminated with radium, probably by the use of some tap grease for a stopcock. This accident brought home to me the danger of making experiments of this character in a laboratory contaminated with radium, so that most of the experimental work recorded in this paper was carried out in the Chemical Laboratory, in which no radioactive matter had been introduced.

At the same time that the actinium solution had been prepared, a quantity of a solid actinium preparation weighing .32 gram of activity ahout 250 times uranium, had been set aside in a closed glass tube. The radium content of a gram of the same sample had been determined in 1904 by comparison with a standard radium solution prepared at that time. Corrected in terms of the recently prepared radium standards of Rutherford and Boltwood, the amount of radium per gram of actinium in 1904 was $1.16 \times 10^{-8}$ gram. Assuming, as was probable, that the content of radium was equally distributed throughout the whole mass of the actinium, the amount of radium in the 32 gram was $3.7 \times 10^{-9}$ gram. After an interval of $2 \cdot 7$ years this actinium was removed and dissolved in hydrochloric acid, and the amount of radium present was found by the emanation method, described later, to be $1.05 \times 10^{-8}$ gram. The growth of radium in the interval of 2.70 years between the two tests was thus $6.9 \times 10^{-9}$ gram, or assuming the rate of growth constant $2.9 \times 10^{-9}$ gram per year. While not much weight can be attached to this result by itself, on account of the imperfect aspiration method employed in the initial determination of the radium constant, yet the rate of growth observed will be seen to be 
in good agreement with that determined later for a similar preparation.

\section{§3. Experimental Methods.}

Before considering further experiments, a brief description will be given of the experimental methods employed to determine accurately the quantity of radium in the various preparations. The preparation was obtained in the form of a solution and placed in a glass flask. The solution was then boiled to expel completely all the emanation, and the exittube sealed before the flask had cooled. After a definite time-interval, the flask was opened and the air, mixed with emanation, was expelled by vigorous boiling and collected over water. Boltwood has shown that boiling is the only satisfactory method of expelling all the radium emanation. The air plus emanation was then introduced through a dryingtube of phosphorus pentoxide into an exhausted electroscope of capacity greater than the volume of air to be introduced. Air was then let in to fill the electroscope to atmospheric pressure and the electroscope closed. The electroscope employed in most of these experiments consisted of an Erlenmeyer tlask of about 1 litre capacity silvered on the inside, in which the gold-leaf system was insulated after Wilson's method by a sulphur bead. The motion of the gold-leaf was read through openings in the silvering by a microscope with a scale in the eyepiece in the usual manner. The natural leak of the electroscope was small and corresponded to $\cdot 14$ division per minute of the scale in the eyepiece. Since the emanation from $10^{-9}$ gram of radium in equilibrium produced a movement of 11.5 divisions per minute, the natural leak was equivalent to that produced by $1.2 \times 10^{-11}$ gram of radium. As is generally observed, the natural leak increased gradually for several days on standing, probably due to a small trace of radium present, but always came back to the same value if the electroscope was exhausted and refilled two hours before observations were begun. Since the vessel was always exbausted to introduce fresh emanation, this peculiarity of the electroscope was no disadvantage. The natural leak tested in this way was remarkably steady, and never varied more than ten per cent. over the course of several months.

Readings of the movements of the gold-leaf were commenced three hours after the introduction of the emanation. At this time, the active deposit is nearly in equilibrium with the emanation, and there is only a very slight change of the rate of movement for several hours. The electroscope was calibrated and standardized by means of the emanation from 
a standard solution of radium bromide, prepared by Rutherford and Boltwood. For the above electroscope the emanation from $10^{-9}$ gram of radium gave a movement of the gold-leaf of 11.5 divisions per minute.

An amount of emanation which increased the natural leak by ten per cent. could be detected with certainty, so that the electroscope was capable of showing the presence of $10^{-12}$ of a gram of radium in a solution. Ten times this quantity could be measured with a probable error not more than a few per cent.

In the experiments to be described later, it will be shown that there was a constant rate of growth of radium in most of the solutions under examination. Since the amount of emanation in the various solutions was determined at irregular intervals, it is necessary to consider how the electroscope readings are connected with the amount of radium existing in the solution at the moment of expulsion of the emanation.

Let $q_{0}=$ amount of radium present initially.

Let $q=$ rate of growth of radium.

Then after the solution has stood for a time $t$, the amount of radium present is $q_{0}+q . t$.

Suppose that the emanation is completely removed after a time $t_{1}$ since the preparation of the solution, and is tested for the amount of emanation after a further interval $t_{2}$. If a constant quantity of radium is allowed to produce emanation for a time $t$, it is well-known that the fraction of the equilibrium quantity of emanation produced is $1-e^{-\lambda t}$, where $\lambda$ is the constant of decay of the radium emanation.

Consequently the amount of emanation present after a time of collection $t_{1}$ is proportional to

$$
\left(q_{0}+q t_{1}\right)\left(1-e^{-\lambda t_{2}}\right)+q \int_{0}^{t_{2}}\left(1-e^{-\lambda \overline{t_{2}-t}}\right) d t .
$$

The left-hand side of the expression is proportional to the amount of emanation due to the radium present in the solution at the time $t_{1}$, while the integral is proportioual to the emanation produced by the quantity of radium formed in the interval $t_{2}$.

After reduction, the amount of emanation is seen to be proportional to

$$
\left[q_{0}+q\left(t_{1}-\frac{1}{\lambda}\right)\right]\left(1-e^{-\lambda t_{2}}\right)+q t_{2} . \quad . \quad .
$$

This expression is proportional to the observed rate of movement of the gold-leaf, so that knowing $q_{0}, t_{1}, t_{2}$, and $\lambda$, the value of $q$ may be expressed in terms of divisions per minute of the electroscope.

In all the experiments to be discussed, the value of $q$ was 
found to be constant over the whole time of observation. The value $q_{0}$-the initial amount of radium present-is best determined from the first observation assuming that the rate of growth of radium during the first few days is the same as that found later. As an example of the method of calculation, let us consider the solution labelled actinium II. (see $\S 7$ ). The average rate of growth of radium per week corresponded to $\cdot 26$ divisions per minute of the electroscope; $i$.e., the equilibrium quantity of the cmanation from the amount of radium produced per week would give that rate of movement of the electroscope.

The first measurement was made after an interval of four days, and the emanation from the solution gave $\cdot 050$ division per minute of the electroseope. Since $t_{1}=0$, the equation given above reduces to

$$
\left(q_{0}-\frac{q}{\lambda}\right)\left(1-e^{-\lambda t_{2}}\right)+q t_{2}=\cdot 050 .
$$

For convenience we shall take a week as the unit of time. Since the emanation is half transformed in $3 \cdot 8$ days,

$$
\lambda=1 \cdot 28 \text { (week) }{ }^{-1} ; q=\cdot 26 \text { and } t_{2}=\frac{4}{7} \text { week. }
$$

Substituting these values, $q_{0}=\cdot 02 ; i . e$. , the emanation from the amount of radium initially present in the solution would give a rate of movement of the electroscope of only $\cdot 02$ division per minute-a just detectable quantity.

\section{$\S 4$. New Experiments.}

A part of the contaminated actinium solution, previously mentioned, was chemically treated to free it from radium. For this purpose, ammonium sulphide was added; this precipitated the actinium and left the radium in solution. By two successive precipitations the greater part of the radium was removed. The precipitate was dissolved in hydrochloric acid, and the radium content of the solution tested at intervals. The quantity of radium initially present in the solution (called actinium I.) was found from the first observation by the method already described. The results are given in the following table. Column I. gives the interval since the preparation of the solution; column II. the time of collection of the emanation; column III. the observed movement of the gold-leaf in scale-divisions per minute due to the emanation in the solution. In column IV. is given the value of $q$, the average quantity of radium produced per week, calculated from equation (1) and expressed in terms of divisions per minute of the electroscope. The value of $q$ is calculated from each observation on the assumption that the rate of growth has been constant since the preparation of the solution. 
In column $\mathrm{V}$. is given the value of $q t$, the amount of radium present in the solution at the time of testing.

Growth of Radium in Actinium I.

\begin{tabular}{|c|c|c|c|c|}
\hline I. & II. & III. & IV. & V. \\
\hline $\begin{array}{l}\text { Time in } \\
\text { days. }\end{array}$ & $\begin{array}{c}\text { Time of collection } \\
\text { in days. }\end{array}$ & $\begin{array}{l}\text { Observed movement } \\
\text { of electroscope. }\end{array}$ & $q$. & $q t$. \\
\hline 4 & 4 & $2 \cdot 13$ & $\cdot 56$ & $\cdot 32$ \\
\hline 11 & 7 & $3 \cdot 33$ & .58 & .91 \\
\hline 18 & 7 & 374 & $\cdot 58$ & $1 \cdot 49$ \\
\hline 25 & 7 & $4 \cdot 12$ & .56 & $2 \cdot 00$ \\
\hline 32 & 7 & 453 & $\cdot 56$ & $2 \cdot 56$ \\
\hline 38 & 6 & $4 \cdot 65$ & $\cdot 60$ & $3 \cdot 26$ \\
\hline 53 & 15 & $7 \cdot 25$ & .55 & $4 \cdot 16$ \\
\hline 82 & 29 & $10 \cdot 1$ & .56 & $6 \cdot 56$ \\
\hline \multirow[t]{2}{*}{121} & \multirow[t]{2}{*}{7} & $9 \cdot 36$ & $\cdot 54$ & \multirow[t]{2}{*}{$9 \cdot 33$} \\
\hline & & Mean value & $\ldots \ldots .566$ & \\
\hline
\end{tabular}

The amount of radium initially present corresponded to 3.95 divisions per minute.

Fig. 1.

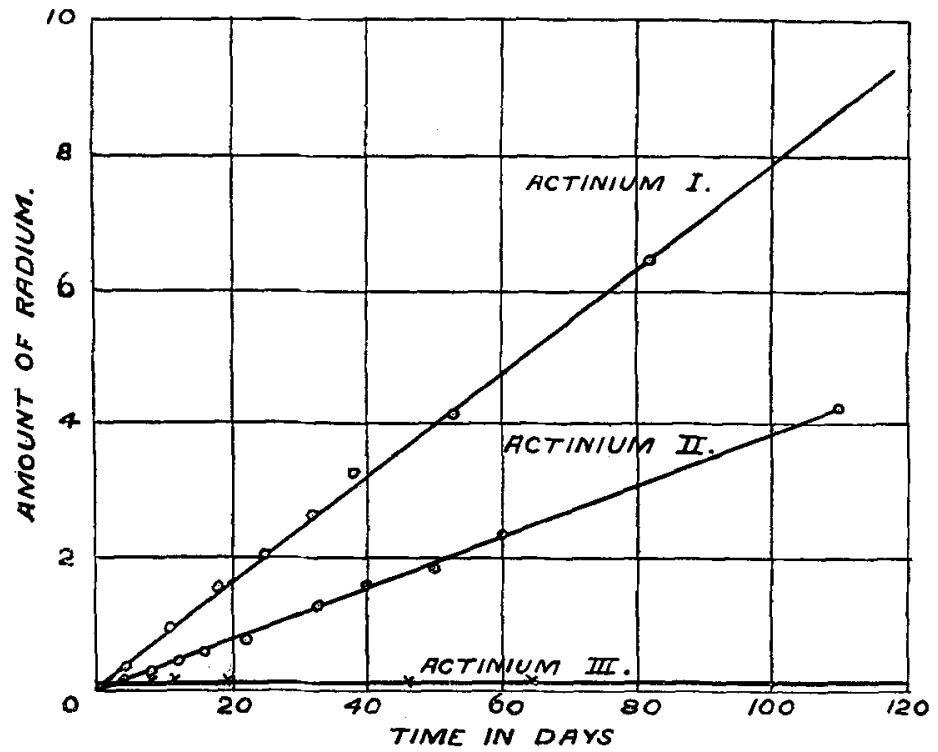

The results are shown graphically in fig. 1 in the curve marked actinium I. The ordinates represent the amount of 
radium present in scale-divisions per minute (taken from column V.), and the ahscisse time in days. It will be seen from the curve and also from column IV. that the rate of growth of radium is constant within the limit of experimental error over the time of observation, viz. 121 days. In that interval, the amount of radium in the solution has increased $2 \cdot 36$ times the initial value. The equilibrium amount of emanation from a standard solution of $10^{-9}$ gram of radium gave 11.5 divisions per minute in the electroscope. The rate of growth of radium in the solution thus was $4.9 \times 10^{-11} \mathrm{gram}$ per week, and assuming the rate of growth constant, $2.55 \times 10^{-9}$ gram per year.

\section{$\S 5$. Activity Measurements.}

In order to follow the results of the chemical operations, the activity due to a definite fraction of the solution was examined over a long interval. 1/2000 of the solution was taken and evaporated to dryness on a watch-glass. This gave an extremely thin film of active matter from which the a rays escaped with little absorption. The a ray activity of this film was tested in an a ray electroscope. The variation

Fig. 2.

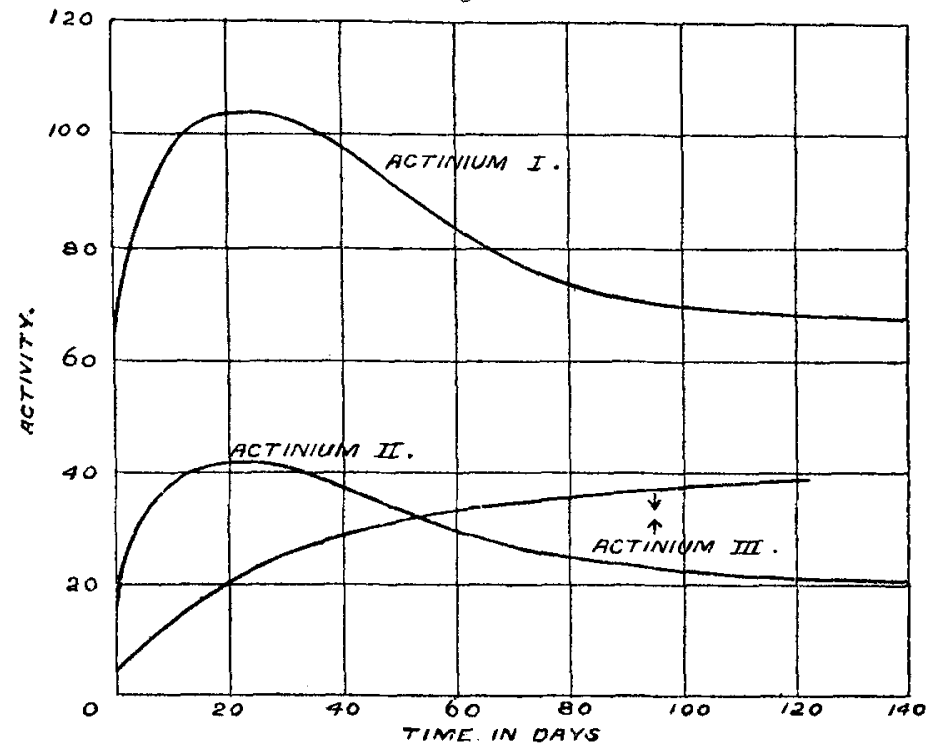

of activity is shown in fig. 2, where the ordinates represent the activity in arbitrary units and the abscissa time in days. Phil. Mag. S. 6. Vol. 14. No. 84. Dec. 1907. $3 \mathrm{D}$ 
It will be seen that the activity at first rises, passes through a maximum in a little over 20 days, and then gradually decays to a constant value about equal to that initially observed. 'Thi decrease of the activity after rising to a maximum shows clearly that some of the actinium had not been precipitated by the ammonium sulphide. In addition, the rise of activity to a maximum in about 20 days shows that an excess of the normal amount of radionctinium was removed with the part of the actinium precipitated. Most of the actinium was left behind in the filtrate. The radioactinium in the precipitate produced fresh actininm $\mathrm{X}$ and the activity rose. The gradual fall of the activity to a constant value is due to the decay of the excess of the radioactinium together with its transformation prodncts. The activity curve will be seen io be very similar to the curves given by Hahn (Phil. Mag. Jan. 1907) for cases where radioactinium is initially in excess. It will be seen that the activity curce is of great value for determining the effect of the chemical operation in removing the various products associated with actinium.

\section{\$6. Further Experiments with Actinium I.}

After an interval of 121 days, the solution was removed, precipitated with ammonia, and the growth of radium in the precipitated actinium again observed. The object of this experiment was to test whether this reagent was as effective as ammonium sulphide in removing radium from actinium, and also whether the substance that produced radinm was precipitated completely with the actinium. Most of the radium was removed by a single precipitation, while the rate of growth of radium in the actinium was unaltered by the process. Such a result is of importance in showing that while radium is soluble in ammonia, the substance that produces it is not, but is precipitated with the actinium. 'The observation of the gron th of radium in the solution has been tested over a further period of 184 days or 305 days in all. There has been no certain chinge in the rate of growth of radium in this interval.

\section{§ 7. Experiments with Actinium II.}

The experiments with actinium I. show that radium is produced at a constant rate in a normal actinium solution, but do not show whether radium is produced from actinium jtself or from another substance ordinarily separated with the actinium. The products of actinium in crder of sequence are radionctinium, actinium $\mathrm{X}$, emanation, actinium $\mathrm{A}$ and 
actinium $B$, with periods of half transformation of 19.5 days, 10 days, 3.9 seconds, 34 ininutes and 1.5 minutes respectively. Is radium the final product of actinium, i. e. is radium formed from actinium $B$ ? There are two methods of attacking this question :

(1) To examine whether the active deposit of radium (composed of actinium A and B) produces radium, or

(2) To test whether the rate of growth in actinium is initially altered by the removal from it of actinium $\mathrm{X}$ or radioactinium.

Fxperiments using the method (1) are described later in $\S 9$ of this paper, bıt we shall here only consider the second method. If radium is produced directly from actinium $B$, the rate of production of radium should be nearly proportional to the amount of actinium $\mathrm{X}$, since after a few hours the rapidly trans lormed products actinium $\mathrm{A}$ and $\mathrm{B}$ are in equilibriun with it. Consequently, if actinium $\mathrm{X}$ is removed from an actinium solution in equilibrium, the rate of growth of radium in the latter should at first be very small, but should gradually increase as fresh actinium $X$ is formed. Since the half period of actinium $X$ is 10 days, the rate of growth of radium should reach half value in 10 days and be within less than two per cent. of the final constant value in about 60 days.

In order to test this point accurately, it is necessary that the solution under examination should initially contain an amount of radium small compared with the growth per week. In the case of actinium $I$, the inirial content of radium was too large to be quite certain that the rate of growth in the first few days was identical with that determined later.

A part of the actinium preparation of weight 0.32 gram, discussed in $\$ 2$, was used for this purpose. It was dissolved in hydrochloric acid and twice precipitated with ammonium sulpbide and finally with ammonia, in order to be sure that the actinium $\mathrm{X}$ as well as the radium was almost completely removed. These operations were successful, for a solution of actinium was obtained whose initial content of radium corresponded to only 02 division per minute in the electroscope, while the rate of growth per week was $\cdot 26$ division. A careful examination of the radium content was made at successive intervals of four days until it was clear that the rate of growth was constant. The results are shown in the following table, and are arranged in the same way as the results in the table for actinium $I$. 
Prof. F. Rutherford on the

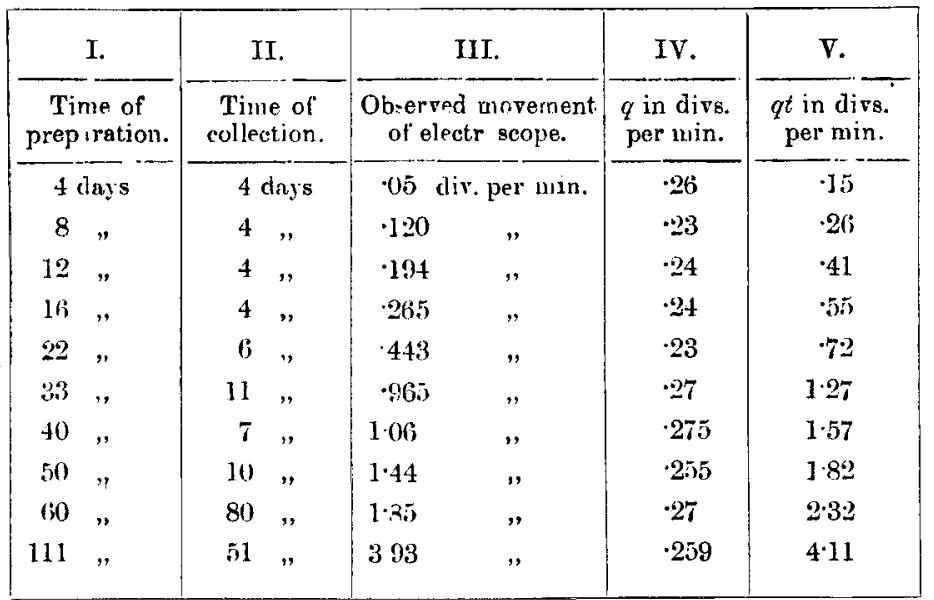

The amount of radium at different times is shown graphically in fig. 1 (curve actinium II.), drawn on the same scale as the curve for actinium II. It will be seen from colunn IV. that the rate of production of radium per week, within the limits of experimental error, is constant over the whole interval of 111 days. If radium had been produced directly from actininm B, the rate of growth observed at an interval of 8 days should have been about $\cdot 11$ or less than half that actually observed. We may thus conclude that (1) radium is not produced directly from actinium $\mathrm{B}$, and (2) that if radium is produced directly from actinium, a product of slow transformation must exist between actinium $\mathrm{B}$ and radium.

On account of my departure from Montreal, the experiments were stopped after 111 days. The electroscope was removed and set up in Manchester and the solution tested at intervals. The results indicate that the rate of growth is still the same after a period of 246 days.

\section{§3. Experiments with Actinium III.}

The variation of the $\alpha$ ray activity of a thin film of the solution actinium II. is shown in fig. 2 on the same scale as that of actinium $\mathrm{I}$. It will be seen that the variation of the activity is very similar to that observed for actinium I., and is to be explained in a similar manner. As in the tirst case, only a part of the actinium was precipitated by the addition of ammonium sulphide. The residue of the actinium remained in the filtrates. After suitable treatment of the latter, ammonia was added in order to precipitate the remaining actinium. A very small precipitate was obtained which was not more than one hurdredth of the weight of that initially 
obtained using ammonium sulphide. This small precipitate contained more than three quarters of the actinium in the original preparation, showing that, under the experimental conditions, a considerable concentration of the actinium had been effected. This small precipitate (called actinium III.) was dissolved in hydrochloric acid and its activity examined. The variation of its activity is shown in fig. 2 (curve actinium III.). The ammonia removed most of the actinium $X$, while most of the radioactinium had been separated with actinium II. The activity consequently rapidly increased, due to the fresh production of radioactinium, and was still rising after an interval of 120 dass. This curve is very similar in shape to that given by Hahn (Phil. Mag. June 1907) for the rise of a ray activity of actinium freed from all its products.

The solution actinium III. was then tested to see if there were any growth of radium in it. The observations are shown in the following table:-

Actinium III.

\begin{tabular}{|c|c|c|}
\hline I. & II. & $11 \mathrm{I}$. \\
\hline $\begin{array}{c}\text { Time in } \\
\text { dass. }\end{array}$ & $\begin{array}{c}\text { Divisions per mimute } \\
\text { of electroscope. }\end{array}$ & $\begin{array}{c}\text { Divisions per minutu } \\
\text { in equilibrium. }\end{array}$ \\
\hline 4 & .071 & $\cdot 140$ \\
8 & $.07 t$ & $\cdot 148$ \\
12 & .077 & $\cdot 154$ \\
19 & 1.07 & $\cdot 151$ \\
415 & 1.39 & $\cdot 139$ \\
64 & 1.30 & $\cdot 135$ \\
\hline
\end{tabular}

Column II. gives the observed rate of leak of the electroscope due to the emanation; column III. the calculated rate of leak of the equilibrium amount of emanation, supposing there was no growth of radium in the solution. Considering the very small rate of leak to be measured, the differences between the numbers in column III. are not greater than the experimental errors. The results thus clearly show that there is no certain growth of radium in the solution. If there is any growth of radium at all, it is certainly less than 02 of a division per minute over a period of 64 days. The growth of the radium per week, in the solution actinium II., which contains only about balf of the actinium in the solution III., corresponds to 26 division or to $2 \cdot 38$ divisions in 64 days. For equal quantities of actinium, the growth of radium in solution III. is certainly less than $1 / 200$ of that observed in solution II. 
In order to make certain that the observed absence of growth of the radium cannot be ascribed to some chemical action, the solution after 64 days was removed and again treated with ammonia. The precipitate was dissolved in hydrochloric and again tested for growth of radium. By this treatment the initial content of radium was reduced from $\cdot 14$ to 04 . No growth of radium was observed over a period of 20 dars. The solution was then removed to Manchester and tested at intervals over a further period of 136 days. The grow th in the total interval of 220 days is certainly less than 03 or not greater than $1 / 500$ of the normal growth to be expected.

§ 9. Experiments with the active deposit.

We have seen in $\S 7$ that the observed constant growth of radium in a solution freed trom actinium $X$ shows that actinium $B$ is not directly transformed into radium. This result has been confirmed by testing directly whether there was any growth of radium in the active deposit of actinium. The active deposit (actinium A and B) was concentrated on a platinum plate by keeping it negatively charged in the presence of the emanation from an active solid preparation of actinium. Four different experiments were tried in which a platinum plate was exposed for $4,7,7$, and 14 days respectively. After exposure, the platinum plate was placed in a solution of hydrochloric acid to dissolve off the deposited matter, and the solution with the platinum plate in situ tested for radium. 'The first two experinents showed a just measurable quantity of radium, but with still greater precautions against radium contamination, the last, two experiments showed no measurable amount. It may be of interest to consider briefly a method of calculating the amount of radium theoretically to be expected, if actinium $B$ changes directly into radium. Suppose as the basis of calculation that the growth of radium in the solution actinium I. (\$4) is normal, and compare the amounts of actinium $B$ in this solution and on the platinum plate. The $\alpha$ ray activity of the actinium and its products in the solution spread in a thin film corresponded to 9900 divisions per minute in the $a$ ray electroscope, while the activity of both sides of the platinum plate, tested immediately after removal from the actinium emanation, was 3800 divisions. Now the actinium in equilibritum contains four a ray products whose ranges are $4 \cdot 8$, $6.55,5 \cdot 8$, and $5.5 \mathrm{cms}$. respectively, while the active deposit contains only one of range $5.5 \mathrm{cms}$. Taking as a first approximation that the ionization due to an $\alpha$ particle from each product is proportional to its range in air, the solution contains an amount of active deposit corresponding to an 
activity of 2400 divisions. Consequently the amount of radium to be expected on the platinum plate is 1.6 of the growth of radium in the solution in the time of exposure of the platinum plate to the constant supply of actinium emanation. Now this solution grew per week an amount of radium corresponding to 56 division per minute of the electroscope. Consequently, on this hypothesis, the platinum plate exposed for two weeks should contain an amount of radium corresponding to 1.8 divisions per minute. The actual amount observed was not more than 01 division, or less than $1 / 180$ of the theoretical amount. Such a result conclusively shows that actinium $B$ does not change directly into radium. It is not inconsistent, however, with the possibility that a slowly changing product exists between actinium $B$ and radium. In such a case radium, in the course of time, should appear in the solution containing the platinum plate.

\section{$\S 10$. Discussion of Results.}

In the following table are given the collected results of the experiments on the growth of radium in the various solutions. In column II. is given the total activity of the preparations when in radioactive equilibrium, expressed in divisions per minute of the a ray electroscone. This activity was determined in each case by taking a definite small fruction of the preparation in solution and eraporating it to dryness on a watch-glass. Column III. gives the observed rate of growth per week expressed in grams of radium. Column III. gives the rate of growth per year, on the assumption that it is constant over that interval. Column V. shows the relative growth of radium for equal quantities of actinium, taking the rate of growth in the solution actinium I. as unity.

\begin{tabular}{|c|c|c|c|c|}
\hline I. & II. & III. & IV. & $\mathbf{v}$. \\
\hline Preparation. & $\begin{array}{l}\text { Total constant } \\
\text { activity of } \\
\text { preparation. }\end{array}$ & $\begin{array}{l}\text { Rate of growth } \\
\text { of radium } \\
\text { per week. }\end{array}$ & $\begin{array}{l}\text { Rate of growth } \\
\text { of radium } \\
\text { per yenr. }\end{array}$ & $\begin{array}{l}\text { Relative } \\
\text { growth of } \\
\text { radium. }\end{array}$ \\
\hline Actinium $I_{\text {. }}$ & 9900 & $4.9 \times 10-11$ gram & $2 \cdot 55 \times 10^{-4}$ gram & 1 \\
\hline Actinium II...... & 3000 & $2.3 \times 10-11$ & $1.2 \times 10^{-9}$ & 1.55 \\
\hline Actinium III. .. & 6000 & not measurable & $\cdots \cdots$ & $\begin{array}{c}\text { not grenter } \\
\text { than } 00^{2}\end{array}$ \\
\hline$\left[\begin{array}{c}32 \text { gram of ac- } \\
\text { tinium tested } \\
\text { over a period } \\
\text { of } 27 \text { year's ... }\end{array} \mid\right.$ & 12900 & $56 \times 10^{-11} \mathrm{gram}$ & $29 \times 10^{-9}$ gram & $\cdot 97$ \\
\hline
\end{tabular}


It is seen from the above table that for equal amounts of actinium, the growth in actinium $I$. is very nearly the same as for the 32 gram, examined over a period of $2 \cdot 7$ years. The closeness of the agreement is no doubt accidental on account of the uncertainty (see $\$ 2$ ) in regard to the initial content of radium in the 32 gram of actinium preparation. The table brings out clearly the differences in the growth of radium in the three solutions for equal quantities of actinium.

The solution actinium II. grows radium at 1.5 times the rate of actinium I., while solution III., if it grows radium at all, certainly does so extremely slowly.

These experiments can all be readily explained on the simple hypothesis that in ordinary actinium preparations there exists a new substance of slow change which is directly transformed into radium. This new substance is separated with the actinium from the mineral by the methods ordinarily employed for the removal of the actinium. It differs, bowever, in chemical properties both from radium and actinium, and by special chemical methods can be separated from them both. For example, the preparation actinium I. may be considered as possessing the normal quantity of the radium producing substance; while the preparation II. contains an excess over the normal. In the case of the solution II., the treatment with ammonium sulphide precipitated all this new substance, but only a fraction of the actinium. The filtrate consequently contained actinium but no trace of the parent of radium. Under such conditions, there was relatively a large growth of radium in the solution II. but none in the solution III.

As far as the investigations have gone, there is no definite evidence whether this new substance is itself produced by actinium, or whether it is merely associated with the actinium in the same sense that barium always appears with the radium. In the former case, the solution III. is gradnally froducing this new substance, and in the course of time there will be an appreciable growth of radium in it. In the latter case, the solution III. will never show any growth of radium comparable with that ordinarily observed. It is not unlikely that this new substance is in reality an intermediate product in the direct line between uraninm and radium, and has no direct genetic connexion with the actinium.

The observed constant growth of radium in the solution shows that the parent of radium has a slow rate of change. At a minimum estimate, its period cannot be less than several years and may be much longer. 


\section{Summary of Results.}

(1) Over the time of observation (?05 days) radium is produced in actinium preparations at a constant rate.

(2) By suitable chemical treatment actinium preparations can be obtained which grow radium extremely slowly.

(3) The active deposit of actiniam does not chinge directly into ridium.

(4) The results indicate that in the ordinary actinium preparations there exists a new substance which is slowly transformed into radium. This direct parent of radium can be chemically sepurated both from actinium and radium.

(5) Observations have not extended over sufficient time to settle whether this direct parent of radium has any direct genetic connexion with actinium or not.

Experiments are in progress to devise more definite methods for separation and isolation of this new substance in order to examine its physical and chemical properties, and to determine its position in the long series of transformations of uranium.

Manchester, Sept. 20, 1907.

LXXIV. On Prof. Lowell's Method for Evaluating the SurfaceTemperatures of the Planets; with an Attempt to Repressut the liffece of Hey and Night on the Temperature of the Earth. By J. H. Poyn'ing, F.R.S.*

DROF. LOWELJ'S paper in the July number of the 1 Philosophical Magazine marks an important advance in the evaluation of planetary temperatures, inasmnch as he takes into account the effect of planetary atmospheres in a much more detailed way than any previous writert. But he pays hardly any attention to the "blanketing effect," or, as I prefer to call it, the "greenhouse effect" of the atmosphere. He assumes in fact that the fourth power of the temperature is proportional to the fraction of solar radiation reaching the surface, and he neglects both the surface

* Communicated by the Author.

+ In Phil. Trans. A. vol. ccii. p. 525 I attempted an evaluation, in which the atmosphere was tuken into account as heeping the temperature at a given point practically the same day and nirht. I did not then know that Christiansen (Beiblatter zu den Ann. cies physik wad Chemie, x. 1886, p. 532) lad nearly twenty year's earlier appied the fourth power law to calculate planetary temperatures. His worli deserves recognition ai the first in which this law was applied. 